\title{
Evaluation of an increased strut porosity silicate-substituted calcium phosphate, SiCaP EP, as a synthetic bone graft substitute in spinal fusion surgery: a prospective, open-label study
}

\author{
Ciaran Bolger ${ }^{1} \cdot$ Drew Jones ${ }^{1,2} \cdot$ Steven Czop ${ }^{2}$
}

Received: 18 July 2018 / Accepted: 30 January 2019 / Published online: 5 March 2019

(c) The Author(s) 2019

\begin{abstract}
Purpose Silicate-substituted calcium phosphate-enhanced porosity ( $\mathrm{SiCaP}$ EP, Inductigraft ${ }^{\mathrm{TM}}$, Altapore) is a synthetic bone graft material with enhanced strut porosity of $31-47 \%$. SiCaP EP remains to be fully clinically evaluated in patients undergoing instrumented posterolateral fusion (PLF) surgery. We conducted a prospective, open-label, non-randomised, multicentre clinical study to evaluate efficacy of SiCaP EP as bone grafting material in PLF surgery with instrumentation for treatment of spinal disorders.

Methods Patients with degenerative disc disease, spondylolisthesis or spinal stenosis underwent PLF surgery with SiCaP EP. The primary endpoint was evaluated in the per protocol population $(N=102)$ as solid fusion at postoperative month 12 assessed using computed tomography scans, with motion assessed using flexion-extension radiographs. Clinical outcomes included the Oswestry Disability Index, 36-item short-form health survey for quality-of-life, visual analog scale for pain scores and neurological assessments. Adverse events were recorded.

Results Successful fusion was achieved in $59 / 89$ (66.3\%) patients at month 6, 88/102 patients (86.3\%) at month 12 (primary endpoint) and 87/96 (90.6\%) patients at month 24. Disability and pain reduced following surgery. Quality-of-life improved and neurological function was maintained postoperatively. Forty-three $(33.3 \%)$ of the 129 patients who underwent surgery experienced adverse events; back pain was most frequent $(n=10)$; nine and 14 patients experienced serious adverse events judged related to device and procedure, respectively.

Conclusions Enhanced strut porosity SiCaP EP provided high (month 12: 86.3\%) spinal fusion success rates in PLF surgery. Fusion success was associated with improved clinical outcomes in patients within 12 months, relative to baseline.
\end{abstract}

ClinicalTrials.gov identifier NCT01452022

\section{Graphical abstract}

These slides can be retrieved under Electronic Supplementary Material.
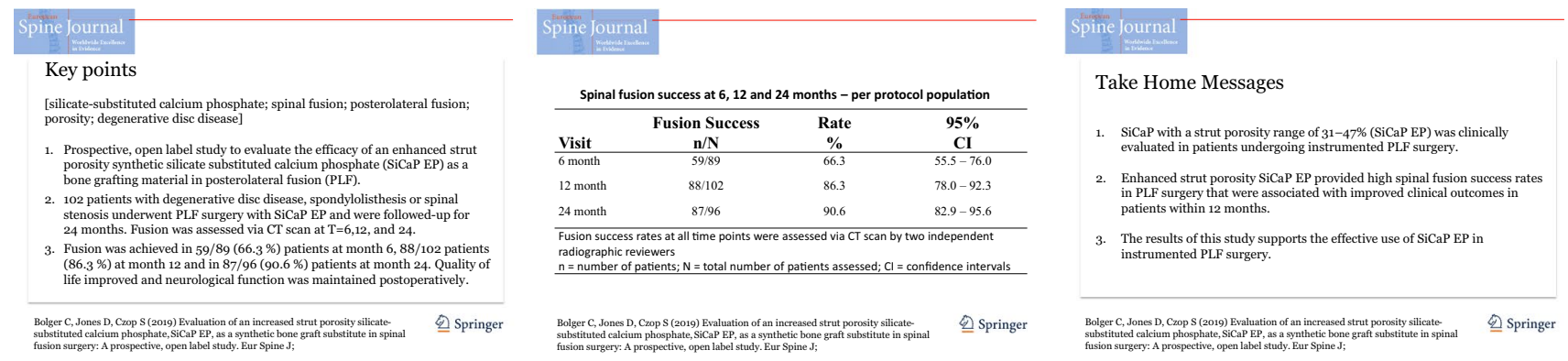

Electronic supplementary material The online version of this article (https://doi.org/10.1007/s00586-019-05926-1) contains supplementary material, which is available to authorized users.

Extended author information available on the last page of the article 
Keywords Silicate-substituted calcium phosphate $\cdot$ Spinal fusion $\cdot$ Posterolateral fusion $\cdot$ Porosity $\cdot$ Degenerative disc disease

\section{Introduction}

Degenerative disc disease, spinal stenosis and spondylolisthesis are major spine pathologies, causing severe chronic back and leg pain, loss of motor control, neurological deficit and impaired quality-of-life [1]. When symptoms prove unresponsive to conservative treatments of bed rest, exercise therapy and analgesics [2,3], patients may undergo spinal fusion surgery to eliminate motion of the vertebral body, prevent further tissue damage and relieve pain, restoring the patient's quality of life [4]. Spinal fusion patients have increased from approximately 170,000 to 410,000 in the USA from 1998 to 2008 [5]. Patients tend to be older, and an ageing population indicates demand for this surgery will increase.

Posterolateral fusion (PLF) surgery coupled with stabilising rigid instrumentation is a reliable, frequently used spinal fusion technique [6]. Autologous iliac crest has been used as a bone graft material [7]; however, it is associated with complications including safely harvesting sufficient bone tissue, haematoma, scarring and infection [8,9]. Cadaveric bone graft materials can be used but lack quality assurance [10] or disease-free status [11]. The growth factor recombinant human bone morphogenetic protein-2 (rhBMP-2) is licensed for spinal fusion surgery, but a meta-analysis concluded that, while it increases the probability of successful fusion, it does not translate to clinically meaningful benefits in pain reduction, function or quality of life [12].

Synthetic bone grafts provide another approach. Silicatesubstituted calcium phosphate $(\mathrm{SiCaP})$ is an alternative synthetic bone graft material containing $0.8 \%$ silicon by weight, similar to levels in naturally growing bone [13]. The silicate ions within the lattice [14] contribute a negative charge at the graft surface promoting bone neovascularisation [15]. To increase bone formation potential, different $\mathrm{SiCaP}$ strut porosity formulations have been developed. Strut pores arise from the interconnecting spaces between calcium phosphate struts in the SiCaP scaffold. The term 'strut porosity' describes the fraction of pore volume for each strut [16].

$\mathrm{SiCaP}$ of $20-25 \%$ strut porosity has been successfully used in PLF surgery $[17,18]$. Based on this, SiCaP-enhanced porosity (EP) has been developed to further increase bone formation by mimicking the microporous osteocyte lacunae network present in physiological bone (see Supplementary Information Figure 1).

The effects of changing strut porosity have been investigated in vitro. SiCaP with a strut porosity of $23 \%$ (SiCaP23) was compared with a formulation of $46 \%$ strut porosity (SiCaP-46). Immersion in simulated body fluid produces small rod-like formations across the surface of SiCaP-23. Larger plate-like formations across the surface of SiCaP46 were observed, consistent with the morphology of hydroxyapatite and octacalcium phosphate, precursors to bone-like apatite [19]. In vitro, SiCaP EP supports greater cell proliferation and early osteoblastic differentiation than $\mathrm{SiCaP}$ and Bioglass $45 \mathrm{~S} 5$ bone graft in the absence of external ostegenic factors [20].

In a rabbit PLF model, $\mathrm{SiCaP}$ with bone marrow aspirate and as an autograft extender produced equivalent spinal fusion rates and quality to autograft [21]. In another rabbit PLF model with concurrent chemotherapy, SiCaP EP demonstrated a statistically higher fusion rate compared with autograft, SiCaP and $\beta$ TCP-bioglass [22].

Although preclinical evidence supports use of SiCaP EP as a stand-alone graft, it remains to be clinically evaluated with long-term follow-up in patients undergoing instrumented PLF surgery. This post-market surveillance of clinical evidence assessed the performance of SiCaP EP, with a strut porosity of up to $47 \%$ (Inductigraft ${ }^{\mathrm{TM}}$, Altapore), in terms of fusion success and clinical, quality-of-life and safety outcomes (ClinTrial: NCT01452022).

\section{Methods}

\section{Hypothesis}

The enhanced strut porosity synthetic silicate-substituted calcium phosphate, Inductigraft ${ }^{\mathrm{TM}}$ (SiCaP EP), can be successfully used as a bone grafting material in PLF surgery.

\section{Study population}

Patients were aged $\geq 18$ years, skeletally mature (epiphyses closed) with a diagnosis within the previous 9 months of lumbar degenerative disc disease or lumbar spinal stenosis, including spondylolisthesis (degenerative or isthmic) and less than three previous decompressive procedures. Patients had failed at least 6 months of non-operative treatment, such as bed rest, physical therapy, bracing, traction and drug therapy prior to enrolment, and were candidates for spinal fusion surgery over 1 or 2 vertebral levels between, and including, L2 to S1 (second lumbar to first sacral). Patients with history of prior fusion surgery or metabolic bone disease such as osteomalacia or autoimmune disease, including rheumatoid arthritis, were ineligible. This study was conducted in compliance with International Conference on Harmonisation (ICH) Good Clinical Practice (GCP), the Declaration 
of Helsinki and all applicable regulations. Patients provided written informed consent before participating in any studyrelated activities.

\section{Study design}

An open-label, phase IV, prospective, multicentre clinical study was conducted in 15 research sites across five countries. Patients underwent PLF surgery with SiCaP EP as the sole graft material, which contains phase-pure, porous $\mathrm{Si}$ substituted CaP granules [1-2 $\mathrm{mm} ; 80-85 \%$ total porosity, $31-47 \%$ micro (or strut) porosity and $0.8 \%$ Si by weight] in aqueous carrier. Pedicle screw and rod instrumentation was used to fuse 1 or 2 levels. Approximately $20 \mathrm{~mL}$ of $\mathrm{SiCaP}$ EP was placed in the posterolateral gutters between the decorticated transverse processes, which were decorticated to their tips.

\section{Study assessments}

Postoperative, radiographic [computerised tomography (CT) scans for fusion and flexion-extension radiographs for motion] and clinical outcomes [Oswestry Disability Index (ODI), visual analog scale (VAS), 36-item short form survey (SF-36) scores and neurological status] were assessed 6, 12 and 24 months after surgery.

Fusion was measured using CT scans performed at a central core laboratory (Medical Metrics, Houston, Texas). Successful fusion was defined as solid unilateral fusion (Grade 4) or solid bilateral fusion (Grade 5) [23] detected by the presence of bone bridging adjacent vertebral bodies through or around the implants (see Supplementary Information Figure 2). No fusion on either side was denoted by Grade 1, partial or limited unilateral fusion by Grade 2 and partial or limited bilateral fusion by Grade 3. Successful fusion was also defined by the absence of motion between the fused vertebral bodies for all treated vertebral levels $(\leq 3 \mathrm{~mm}$ difference in transitional motion and $<5^{\circ}$ difference in angular motion). For patients who received PLF surgery at two vertebral levels, fusion was considered successful if both levels fused. If fusion was absent at month 12 , patients were re-assessed at 24 months.

Clinical outcome measurements included functional disability indicated by ODI scores, back and leg pain evaluated using VAS, quality of life indicated by SF-36 score, and neurological function. Patients achieved clinical success if their ODI score was $\geq 15 \%$ better than their preoperative score. Back and leg pain intensity was measured with VAS scores, and results of SF-36 were summarised as two main components: a physical component summary (PCS) and a mental component summary (MCS). Success was defined as an improvement in quality-of-life status postoperatively compared with preoperative scores.
Neurological status was tested with evaluation of motor, sensory, reflex, straight leg raise, and femoral stretch tests. Neurological success was defined as a maintenance or improvement in all five evaluations.

Safety was evaluated in terms of adverse events and adverse device events; all reviewed by a committee comprising the Principal Investigator, an independent medical expert and a representative from the manufacturer of SiCaP EP.

\section{Statistical methods}

A sample size of 118 , with a $15 \%$ attrition rate, was estimated to allow for 100 evaluable patients. Patients who underwent PLF surgery were included in the safety population. Patients in the safety population who completed $\geq$ one postsurgical assessment were included in the intent-to-treat (ITT) analysis; patients with fusion data (or successful fusion) at 12 months post-surgery and no major protocol deviation comprised the per protocol (PP) population. Categorical variables were recorded as frequencies and percentages; for numeric variables, descriptive statistics were calculated. Computed tomography scan data were presented for the primary endpoint of fusion success observed at 12 months. Secondary endpoints were efficacy variables of fusion success at 6 and 24 months, ODI and pain/functionality scores at 6 and 24 months; percentages of patients achieving neurological success were reported with corresponding two-sided $95 \%$ confidence intervals. Postoperative evaluations for each indicator were compared with baseline.

\section{Results}

\section{Patient disposition}

One hundred and thirty-one patients enrolled at 15 study centres in the UK (six centres), Germany, Spain (three each), Hungary (two) and Republic of Ireland (one). The safety population included $129(98.5 \%)$ patients, the ITT population 125 (95.4\%) patients and the PP population 102 (77.9\%) patients. In total, 107 (81.7\%) patients completed the study. The most frequent reason for non-completion was the requirement for revision surgery following an adverse event that led to withdrawal of the study in nine $(6.9 \%)$ patients. Seven patients (5.3\%) were lost to follow-up, three (2.3\%) withdrew themselves, three $(2.3 \%)$ were withdrawn at the surgeon's discretion, one $(0.8 \%)$ was withdrawn due to an intraoperative screening failure and one $(0.8 \%)$ patient died (Fig. 1). 


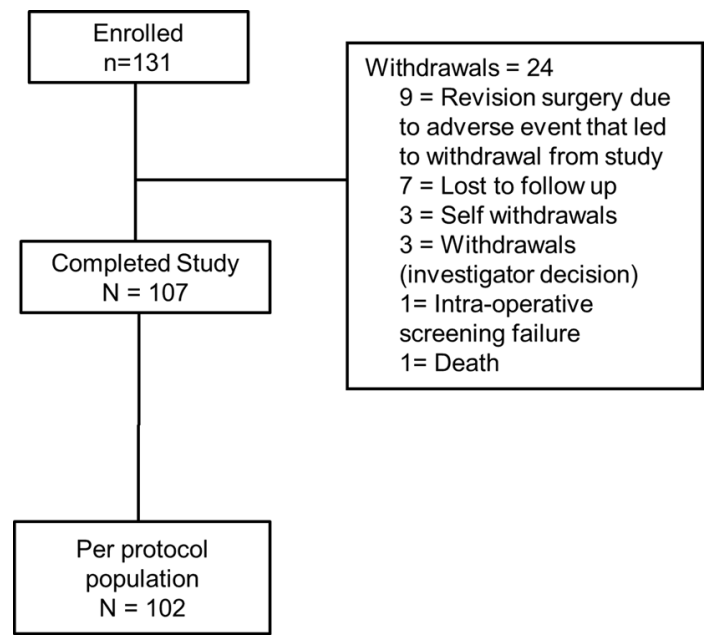

Fig. 1 Study flow diagram. $P P$ per protocol

\section{Patient profile and intraoperative details}

Patients had a mean [standard deviation (SD)] age of 51.9 (13.9) years and mean (SD) weight of $78.0(15.5) \mathrm{kg}$; body mass index (BMI) was $27.25 \mathrm{~kg} / \mathrm{m}^{2}$ and height was $169.0(10.7) \mathrm{cm}$ (Table 1). The proportion of males $[n=59$ $(45.7 \%)]$ and females $[n=70(54.3 \%)]$ was similar, and the prevalence of smokers was $27.6 \%$. Most patients had a diagnosis of degenerative disc disease $[n=79(61.2 \%)]$ with spinal stenosis, isthmic spondylolisthesis, degenerative spondylolisthesis and 'other' conditions also diagnosed. The

Table 1 Patient characteristics—-safety analysis set

\begin{tabular}{ll}
\hline Patient characteristic & $N=129$ \\
\hline Age (years), mean \pm SD & $51.9 \pm 13.9$ \\
Weight $(\mathrm{kg})$, mean $\pm \mathrm{SD}$ & $78.0 \pm 15.5$ \\
Height $(\mathrm{cm})$, mean $\pm \mathrm{SD}$ & $169.0 \pm 10.7$ \\
Body mass index $\left(\mathrm{kg} / \mathrm{m}^{2}\right)$, mean & 27.3 \\
Gender $[n(\%)]$ & \\
Male & $59(45.7)$ \\
Female & $70(54.3)$ \\
Smoking status $[n(\%)]$ & $N=127$ \\
Yes & $35(27.6)$ \\
Smoker $(>10$ units/day) & $20(15.7)$ \\
Smoker $(\leq 10$ units/day) & $15(11.8)$ \\
Primary diagnosis & \\
Degenerative disc disease $(n)$ & $79(61.2)$ \\
Spinal stenosis $(n)$ & $21(16.3)$ \\
Spondylolisthesis $(n)$ & $27(20.9)$ \\
Degenerative spondylolisthesis $(n)$ & $21(16.3)$ \\
Isthmic $(n)$ & $6(4.7)$ \\
SD $=$ standard deviation & \\
\hline
\end{tabular}

Table 2 Spinal fusion success at 6, 12 and 24 months-per protocol population

\begin{tabular}{llll}
\hline Visit & Fusion success, $n / N$ & Rate $\%$ & $95 \%$ CI \\
\hline 6 month & $59 / 89$ & 66.3 & $55.5-76.0$ \\
12 month & $88 / 102$ & 86.3 & $78.0-92.3$ \\
24 month & $87 / 96$ & 90.6 & $82.9-95.6$ \\
\hline
\end{tabular}

Fusion success rates, at each postoperative visit, as judged by two independent radiographic reviewers at the specified levels

$n$ number of patients; $N$ total number of patients assessed; $C I$ confidence intervals
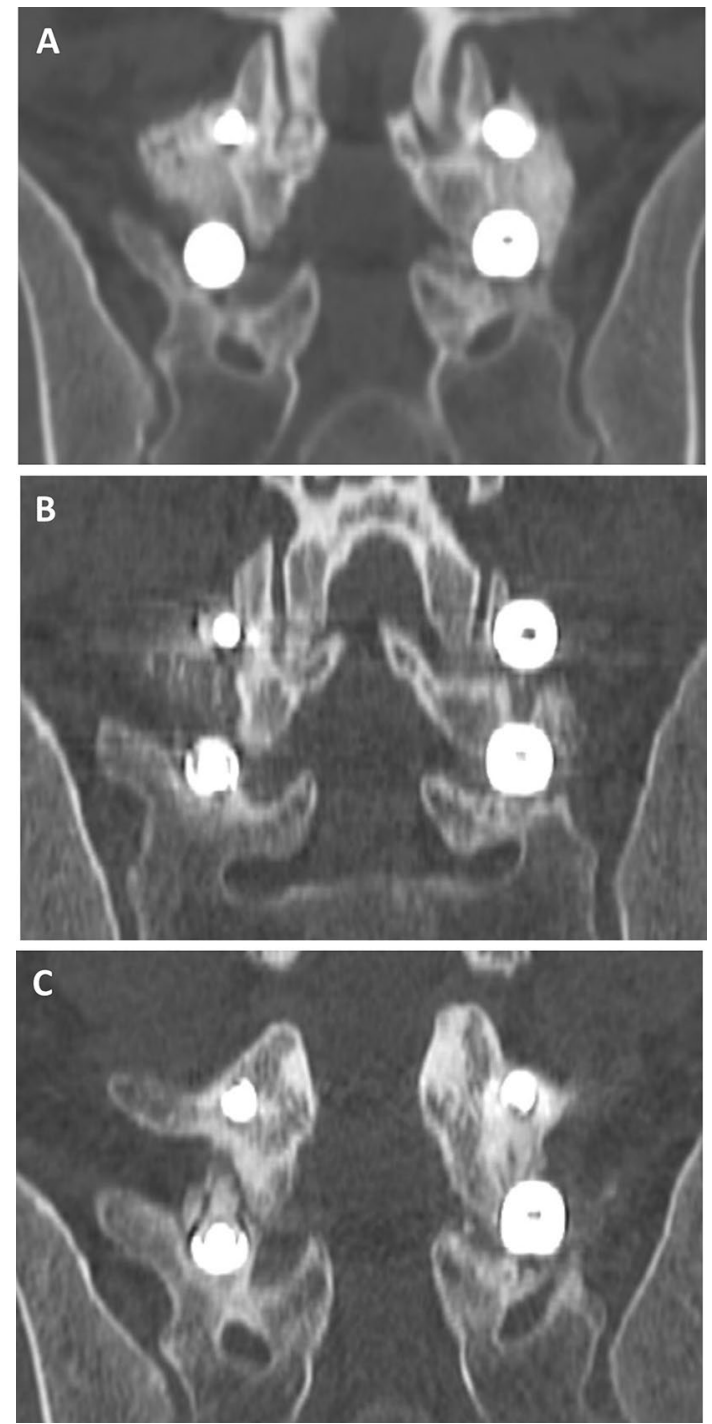

Fig. 2 Representative computed tomography slices to illustrate development of fusion in an example subject. At 6 months (a), this patient displayed Grade 3 Glassman Fusion. Signs of partial bilateral bridging in combination with the graft material were present. Sagittal slices showed that the bridging was not complete on the left or right side of L5-S1 (see Supplementary Information Figure 3). At month 12 (b) and month 24 (c), a complete bridge was visible, bringing the subject to Grade 4 . This bridge was faint at month 12 but more pronounced and evident at month 24 
Table 3 Oswestry disability index (ODI) and visual analog scales (VAS) assessment outcomes-per protocol population

\begin{tabular}{|c|c|c|c|c|}
\hline Visit & Mean score & $\begin{array}{l}\text { Mean change from } \\
\text { baseline }\end{array}$ & $95 \% \mathrm{CI}$ & $P$ value \\
\hline \multicolumn{5}{|l|}{$O D I$} \\
\hline Baseline & $46.6(n=99)$ & - & - & - \\
\hline 6 months & $26.2(n=88)$ & $-20.6(n=87)$ & -24.5 to -16.8 & $<0.0001$ \\
\hline 12 months & $24.4(n=100)$ & $-22.4(n=97)$ & -26.3 to -18.5 & $<0.0001$ \\
\hline 24 months & $33.4(n=17)$ & $-19.7(n=14)$ & -34.0 to -5.4 & 0.0105 \\
\hline \multicolumn{5}{|l|}{$V A S$} \\
\hline \multicolumn{5}{|l|}{ Back pain } \\
\hline Baseline & $5.7(n=99)$ & - & - & - \\
\hline 6 months & $2.5(n=87)$ & $-3.3(n=86)$ & -3.9 to -2.8 & $<0.0001$ \\
\hline 12 months & $2.7(n=98)$ & $-3.1(n=95)$ & -3.7 to -2.4 & $<0.0001$ \\
\hline 24 months & $4.1(n=17)$ & $-3.4(n=14)$ & -5.4 to -1.5 & 0.0023 \\
\hline \multicolumn{5}{|c|}{ Right leg/buttock pain } \\
\hline Baseline & $4.2(n=99)$ & - & - & - \\
\hline 6 months & $1.6(n=87)$ & $-2.6(n=86)$ & -3.3 to -1.9 & $<0.0001$ \\
\hline 12 months & $1.6(n=98)$ & $-2.7(n=95)$ & -3.4 to -2.0 & $<0.0001$ \\
\hline 24 months & $2.5(n=17)$ & $-2.2(n=14)$ & -3.8 to -0.6 & 0.0106 \\
\hline \multicolumn{5}{|c|}{ Left leg/buttock pain } \\
\hline Baseline & $4.2(n=99)$ & - & - & - \\
\hline 6 months & $1.9(n=87)$ & $-2.5(n=86)$ & -3.2 to -1.7 & $<0.0001$ \\
\hline 12 months & $1.5(n=98)$ & $-2.7(n=95)$ & -3.4 to -2.0 & $<0.0001$ \\
\hline 24 months & $2.9(n=17)$ & $-1.1(n=14)$ & -3.0 to 0.8 & 0.2178 \\
\hline \multicolumn{5}{|l|}{ Total pain } \\
\hline Baseline & $4.73(n=99)$ & - & - & - \\
\hline 6 months & $2.01(n=87)$ & $-2.80(n=86)$ & -3.28 to -2.33 & $<0.0001$ \\
\hline 12 months & $1.92(n=98)$ & $-2.84(n=95)$ & -3.32 to -2.36 & $<0.0001$ \\
\hline 24 months & $3.19(n=17)$ & $-2.26(n=14)$ & -3.45 to -1.06 & 0.0013 \\
\hline
\end{tabular}

The ODI is a self-administered questionnaire measuring back-specific function on a 10-item scale, ODI rates spine-specific disability on a scale of 0 to 100 , where 100 is the worst disability

$C I$ confidence interval, $O D I$ Oswestry Disability Index, $V A S$ visual acuity score; $n$ number of patients most frequent concurrent medical condition was hypertension $[n=47(36.7 \%)]$ followed by cardiovascular disease, gastrointestinal disease and diabetes (non-insulin-dependent). Fifty-eight patients $(45.3 \%)$ had no other concurrent medical conditions.

Surgery lasted approximately $2.5 \mathrm{~h}$, and average blood loss was $381.3 \mathrm{~mL}$. The number of pedicle screws used during PLF surgery were eight $[n=1(0.8 \%)]$, six $[n=44(34.1 \%)]$ or four $[n=84(65.1 \%)]$. A mean volume of $24.8 \mathrm{~mL} \mathrm{SiCaP}$ EP was used.

\section{Radiographic assessments}

For the primary endpoint, successful fusion occurred in $88 / 102(86.3 \%)$ patients at month 12 (PP population, Table 2). At month 6, 59/89 (66.3\%) patients achieved fusion and at month 24 in 87/96 (90.6\%) patients. Sensitivity analysis with the ITT population showed a similar result. The pattern of bone fusion grades at postoperative visits was similar for patients with 1 or 2 level fusions. Proportions of patients with a fusion Grade 4 or 5 were $86.4 \%$ (57/66) for 1 level and 91.2\% (31/34) for 2 levels at 12 months, respectively. Example images of fusion progression are presented in Fig. 2.

\section{Clinical outcomes}

\section{Pain scores and disability status}

Mean change from baseline ODI scores crossed the defined threshold of $15 \%$ for improvement from baseline. At months 6, 12 and 24, mean change in ODI scores were -20.6 $(n=87),-22.4(n=97)$ and $-19.7(n=14)$, respectively (Table 3 ). Visual analog scale scores demonstrated patients had reduced pain levels for the majority of measured pain domains at month 6 and month 12 (Table 3). Back and leg pain was significantly reduced at month 24 with the exception of left leg/buttock pain. 
Table 4 Quality of life scores and change from baseline-per protocol population

\begin{tabular}{|c|c|c|c|c|c|}
\hline SF-36 domain & Visit (month) & Mean score & $\begin{array}{l}\text { Mean change } \\
\text { from baseline }\end{array}$ & $95 \% \mathrm{CI}$ & $P$ value \\
\hline \multirow[t]{4}{*}{ Physical functioning } & Baseline & $36.34(n=100)$ & - & - & - \\
\hline & 6 & $60.88(n=88)$ & $26.12(n=87)$ & 21.14 to 31.11 & $<0.0001$ \\
\hline & 12 & $65.17(n=100)$ & $28.75(n=98)$ & 23.82 to 33.68 & $<0.0001$ \\
\hline & 24 & $58.24(n=17)$ & $29.00(n=15)$ & 15.71 to 42.29 & 0.0004 \\
\hline \multirow[t]{4}{*}{ Role-physical } & Baseline & $28.58(n=100)$ & - & - & - \\
\hline & 6 & $54.04(n=88)$ & $24.97(n=87)$ & 18.46 to 31.49 & $<0.0001$ \\
\hline & 12 & $59.83(n=100)$ & $31.06(n=98)$ & 24.73 to 37.39 & $<0.0001$ \\
\hline & 24 & $51.12(n=17)$ & $24.17(n=15)$ & 11.97 to 36.36 & 0.0008 \\
\hline \multirow[t]{4}{*}{ Bodily pain } & Baseline & $22.10(n=100)$ & - & - & - \\
\hline & 6 & $51.40(n=88)$ & $29.85(n=87)$ & 24.31 to 35.39 & $<0.0001$ \\
\hline & 12 & $54.35(n=100)$ & $32.06(n=98)$ & 26.11 to 38.01 & $<0.0001$ \\
\hline & 24 & $38.53(n=17)$ & $19.47(n=15)$ & 8.21 to 30.73 & 0.0023 \\
\hline \multirow[t]{4}{*}{ General health } & Baseline & $55.36(n=100)$ & - & - & - \\
\hline & 6 & $61.63(n=88)$ & $8.37(n=87)$ & 3.85 to 12.89 & 0.0004 \\
\hline & 12 & $62.67(n=100)$ & $7.51(n=98)$ & 3.33 to 11.69 & 0.0006 \\
\hline & 24 & $53.24(n=17)$ & $8.13(n=15)$ & -1.56 to 17.83 & 0.0936 \\
\hline \multirow[t]{4}{*}{ Vitality } & Baseline & $39.65(n=100)$ & - & - & - \\
\hline & 6 & $53.00(n=88)$ & $13.79(n=87)$ & 9.26 to 18.33 & $<0.0001$ \\
\hline & 12 & $54.84(n=100)$ & $16.14(n=98)$ & 11.72 to 20.55 & $<0.0001$ \\
\hline & 24 & $47.81(n=17)$ & $13.33(n=15)$ & -0.68 to 27.35 & 0.0606 \\
\hline \multirow[t]{4}{*}{ Social functioning } & Baseline & $46.25(n=100)$ & - & - & - \\
\hline & 6 & $67.47(n=88)$ & $20.40(n=87)$ & 13.57 to 27.24 & $<0.0001$ \\
\hline & 12 & $69.13(n=100)$ & $22.83(n=98)$ & 16.36 to 29.30 & $<0.0001$ \\
\hline & 24 & $60.29(n=17)$ & $21.67(n=15)$ & 6.31 to 37.03 & 0.0091 \\
\hline \multirow[t]{4}{*}{ Role-emotional } & Baseline & $59.67(n=100)$ & - & - & - \\
\hline & 6 & $69.03(n=88)$ & $8.14(n=87)$ & 0.91 to 15.37 & 0.0278 \\
\hline & 12 & $72.00(n=100)$ & $12.24(n=98)$ & 5.43 to 19.06 & 0.0006 \\
\hline & 24 & $72.06(n=17)$ & $16.66(n=15)$ & -1.04 to 34.36 & 0.0631 \\
\hline \multirow[t]{4}{*}{ Mental health } & Baseline & $56.88(n=100)$ & - & - & - \\
\hline & 6 & $65.24(n=88)$ & $8.66(n=87)$ & 3.29 to 14.04 & 0.0019 \\
\hline & 12 & $69.49(n=100)$ & $12.87(n=98)$ & 8.21 to 17.54 & $<0.0001$ \\
\hline & 24 & $65.29(n=17)$ & $14.83(n=15)$ & 0.94 to 28.72 & 0.038 \\
\hline \multirow[t]{4}{*}{ Reported health transition } & Baseline & $4.06(n=100)$ & - & - & - \\
\hline & 6 & $1.90(n=88)$ & $-2.14(n=87)$ & -2.43 to -1.85 & $<0.0001$ \\
\hline & 12 & $1.71(n=100)$ & $-2.34(n=98)$ & -2.61 to -2.07 & $<0.0001$ \\
\hline & 24 & $3.06(n=17)$ & $-0.73(n=15)$ & -1.58 to 0.12 & 0.0853 \\
\hline \multirow[t]{4}{*}{ Global physical health } & Baseline & $35.60(n=100)$ & - & - & - \\
\hline & 6 & $56.99(n=88)$ & $22.33(n=87)$ & 17.86 to 26.79 & $<0.0001$ \\
\hline & 12 & $60.51(n=100)$ & $24.84(n=98)$ & 20.54 to 29.15 & $<0.0001$ \\
\hline & 24 & $50.28(n=17)$ & $20.19(n=15)$ & 10.71 to 29.68 & 0.0004 \\
\hline \multirow[t]{4}{*}{ Global mental health } & Baseline & $50.61(n=100)$ & - & - & - \\
\hline & 6 & $63.69(n=88)$ & $12.75(n=87)$ & 7.58 to 17.92 & $<0.0001$ \\
\hline & 12 & $66.36(n=100)$ & $16.02(n=98)$ & 11.39 to 20.65 & $<0.0001$ \\
\hline & 24 & $61.37(n=17)$ & $16.63(n=15)$ & 4.86 to 28.41 & 0.009 \\
\hline
\end{tabular}

$C I$ confidence interval, $S F-36 v 2$ health survey formulated by the medical outcomes trust

\section{Quality of life and neurological status}

Mean quality-of-life scores increased for all mental and physical components at month 6 and month 12 . Significant improvements had occurred in seven of the 11 components at month 24 (Table 4). Overall more than half the patients experienced neurological success. Success rates for overall neurological status (patient success in all five parameters) 
Table 5 Neurological status success-per protocol population

\begin{tabular}{lclll}
\hline Neurological status & Visit & Success $^{\mathrm{a}}$ & Rate $\%$ & $95 \%$ CI \\
& Months & $N=102$ & & \\
\hline Motor & 6 & $79(n=88)$ & 89.8 & $81.5-95.2$ \\
& 12 & $91(n=98)$ & 92.9 & $85.8-97.1$ \\
Sensory & 24 & $16(n=17)$ & 94.1 & $71.3-99.9$ \\
& 6 & $69(n=88)$ & 78.4 & $68.4-86.5$ \\
\multirow{4}{*}{ Reflexes } & 12 & $76(n=98)$ & 77.6 & $68.0-85.4$ \\
& 24 & $15(n=17)$ & 88.2 & $63.6-98.5$ \\
Straight leg raise & 6 & $70(n=88)$ & 79.5 & $69.6-87.4$ \\
& 12 & $78(n=97)$ & 80.4 & $71.1-87.8$ \\
& 24 & $11(n=17)$ & 64.7 & $38.3-85.8$ \\
Femoral stretch & 6 & $80(n=88)$ & 90.9 & $82.9-96.0$ \\
& 62 & $92(n=97)$ & 94.8 & $88.4-98.3$ \\
& 12 & $14(n=17)$ & 82.4 & $56.6-96.2$ \\
Overall & $61(n=88)$ & 92.0 & $84.3-96.7$ \\
& 24 & $15(n=17)$ & 88.2 & $63.6-98.5$ \\
& 6 & $45(n=88)$ & 51.1 & $40.2-61.9$ \\
& 12 & $56(n=95)$ & 58.9 & $48.4-68.9$ \\
& 24 & $9(n=17)$ & 52.9 & $27.8-77.0$ \\
\hline
\end{tabular}

CI confidence interval

${ }^{a}$ Maintenance or improvement, except for overall which is maintenance or improvement in all five neurological evaluations

were $51.1 \%$ at month $6,58.9 \%$ at month 12 and $52.9 \%$ at month 24 (Table 5).

\section{Safety}

Forty-three (33.3\%) patients experienced at least one adverse event. Nine (7\%) patients experienced mild adverse events, $13(10.1 \%)$ experienced moderate and $19(14.7 \%)$ experienced severe (Table 6). Nine patients $(7 \%)$ were withdrawn because of adverse events, six of which were judged related to treatment. Seven of these had device component issues [loosening of screws $(n=6)$ or breakage $(n=1)$ ], one had joint instability and one patient died during follow-up; a 68-year-old female who experienced ileus approximately 1 year postoperation. The investigators judged the event unrelated to device or procedure.

The most frequent adverse event was back pain, reported by $10(8 \%)$ patients, followed by device component issues in seven patients (5\%), sciatica in six (5\%) and osteoarthritis in three (2\%). Thirty-two patients $(24.8 \%)$ had a serious adverse event. Serious adverse events related to the device or procedure were experienced by nine (7\%) and fourteen (10.9\%) patients, respectively. The most frequently reported serious adverse event related to device or procedure was back pain in nine patients (7\%), followed by device component issues in six (4.7\%), sciatica in five (4\%) and arthralgia and myositis in two patients each (2\%). Unexpected device-related adverse effects were reported in two patients (1.6\%: one patient experienced myositis and one nerve root compression).

\section{Discussion}

This was the first prospective evaluation of efficacy and safety of a high-porosity $\mathrm{SiCaP}$ (SiCaP EP) in patients with degenerative disc disease, spondylolisthesis and spinal stenosis undergoing instrumented PLF procedures. The primary endpoint of solid fusion at month 12 was achieved in $86.3 \%$ of patients, accompanied by clinically significant decreases in disability at all follow-up visits. Patients also reported reductions in pain and an improved quality-of-life post-surgery. Motor, sensory functions, reflexes, straight leg raise and femoral stretches were either maintained or improved in over half of patients. The study design did not include a comparator treatment, so no direct comparison can be made. However, the fusion rate of $86.3 \%$ at month 12 with SiCaP EP is an improvement in rates of $52-80 \%$ [24, 25], observed with traditional autologous iliac crest and allograft material in PLF surgery.

Instrumented PLF is a reliable technique leading to lasting improvement [6]; however, care should be taken when comparing fusion rates as these vary according to surgery type and no general consensus regarding the suitability of available procedures exists [26]. Previous studies have used $\mathrm{SiCaP}$ with strut porosities of $20-25 \%$ in a range of surgical procedures and evaluated the radiographic and clinical outcomes. In a retrospective study of 42 patients who underwent PLF with $\mathrm{SiCaP}$ as the bone graft material, fusion rates of $76 \%$ were observed [17]. In retrospective studies, 108 patients who underwent spinal fusion procedures including PLF with $\mathrm{SiCaP}$ demonstrated fusion rates of $90 \%$ at a follow-up of $12 \pm 4.7$ months [27]. The fusion rate of $86.3 \%$ achieved in the current study falls within the range of previous studies.

Approximately $33 \%$ of patients reported adverse events, $14 \%$ experienced adverse events related to the procedure and fewer patients (7\%) experienced implant-related events. Despite complications arising from adverse events, the rates of adverse events were well within the range expected, and it is known that these events frequently occur during follow-up periods [28].

Smoking status is reported to affect the success of bone healing [29], spinal fusion [30] and pain relief after decompressive lumbar surgery [31]. The effect of smoking on bone healing and fusion rates is attributed to the effect of nicotine on revascularisation of bone grafts [31]. Although 
Table 6 Summary of adverse events (safety population)

\begin{tabular}{|c|c|}
\hline Description & $\begin{array}{l}n(\%) \\
\text { Total patients }=129\end{array}$ \\
\hline Any adverse event (worst severity experienced) & $43(33.3)$ \\
\hline Mild & $9(7.0)$ \\
\hline Moderate & $13(10.1)$ \\
\hline Severe & $19(14.7)$ \\
\hline Life-threatening & $1(0.8)$ \\
\hline Fatal & $1(0.8)$ \\
\hline Adverse events related to device & $9(7.0)$ \\
\hline Likely related & $7(5.4)$ \\
\hline Definitely related & $2(1.6)$ \\
\hline Adverse events related to procedure & $18(14.0)$ \\
\hline Likely related & $9(7.0)$ \\
\hline Definitely related & $9(7.0)$ \\
\hline Serious adverse event & $32(24.8)$ \\
\hline Serious adverse event related to device & $9(7.0)$ \\
\hline Serious adverse event related to procedure & $14(10.9)$ \\
\hline \multicolumn{2}{|l|}{ Serious adverse events by system organ class ( $>1$ patient) } \\
\hline Musculoskeletal and connective tissue disorders & $17(13.2)$ \\
\hline Back pain & $9(7.0)$ \\
\hline Arthralgia & $2(1.6)$ \\
\hline Myositis & $2(1.6)$ \\
\hline Nervous system disorders & $10(7.8)$ \\
\hline Sciatica & $5(3.9)$ \\
\hline General disorders and administration site conditions & $7(5.4)$ \\
\hline \multicolumn{2}{|l|}{ Device component issue } \\
\hline Gastrointestinal disorders & $6(4.7)$ \\
\hline Neoplasms benign, malignant and unspecified & $2(1.6)$ \\
\hline Unanticipated device-related adverse event & $2(1.6)$ \\
\hline Device revision needed due to an adverse event & $9(7.0)$ \\
\hline An adverse event leading to study withdrawal & $9(7.0)$ \\
\hline
\end{tabular}

no analysis investigating the effects of smoking was conducted, fusion success did not appear to be compromised. This requires further investigation as a risk factor for failed fusion. The average BMI of the study population indicated that the population was overweight, but not obese. Obesity is a risk factor for poor fusion, so the limited number of obese subjects in our study could be considered a limitation as we were unable to assess the efficacy of SiCaP EP in this specific population.

Using the grafting material, rhBMP-2 can achieve fusion rates of $81-100 \%$ [32, 33]. However, a study using a rhBMP-2 bone graft substitute in PLF observed constipation in $11 / 42$ patients and pyrexia in $9 / 42$ patients [33], and the complication rate for rhBMP-2 in posterior lumbar interbody fusion was $41.2 \%$ [29]. A review of 277 patients that underwent anterior or posterior lumbar fusion with rhBMP-2 demonstrated a $22.8 \%$ complication rate, $5.9 \%$ of which were rhBMP-2 related [34]. High doses of rhBMP-2 increased the risk of developing heterogenous cancers compared with receiving iliac crest bone or artificial discs [35]. Nevertheless, extensive review of the published studies raising concerns on rhBMP-2 safety had methodological limitations and so should be interpreted with caution [12].

Use of SiCaP EP in this study demonstrated similar efficacy to previous reports with BMP-2 and may provide an alternative bone grafting option while avoiding potential safety concerns. Recent work has demonstrated the application for stem cell augmentation in spinal fusion surgery with $\mathrm{SiCaP}$ and other grafts. However, the contribution of different cell types has yet to be identified definitively [36].

In summary, the current study satisfies our hypothesis by demonstrating fusion success in PLF surgery using SiCaP EP with a higher strut porosity of up to $47 \%$. The high microporosity of the SiCaP EP matrix allows for bone implant contact which may further encourage natural bone growth and increase the likelihood of successful fusion. The results of this study indicate the potential use 
of SiCaP EP in instrumented PLF surgery. Further studies are warranted to investigate the long-term effects and quality of natural bone formation resulting from using a high-porosity SiCaP bone graft.

Acknowledgements Laila Guzadhur, PhD. and Ryan Russell, PhD. from Niche Science and Technology (Richmond-Upon-Thames, London, United Kingdom) provided writing and editorial support during the development of this manuscript; these services, along with the study, were paid for by Baxter Healthcare.

\section{Compliance with ethical standards}

Conflict of interest Drew Jones and Steven Czop were employed by Baxter Healthcare. Ciaran Bolger has no conflict of interest to declare.

Open Access This article is distributed under the terms of the Creative Commons Attribution 4.0 International License (http://creativeco mmons.org/licenses/by/4.0/), which permits unrestricted use, distribution, and reproduction in any medium, provided you give appropriate credit to the original author(s) and the source, provide a link to the Creative Commons license, and indicate if changes were made.

\section{References}

1. Katz JN (1995) Lumbar spinal fusion. Surgical rates, costs, and complications. Spine (Phila Pa 1976) 20(24 Suppl):78S-83S

2. Koc Z, Ozcakir S, Sivrioglu K, Gurbet A, Kucukoglu S (2009) Effectiveness of physical therapy and epidural steroid injections in lumbar spinal stenosis. Spine 34:985-989

3. Gore M, Sadosky A, Stacey BR, Tai KS, Leslie D (2012) The burden of chronic low back pain: clinical comorbidities, treatment patterns, and health care costs in usual care settings. Spine 37:E668-E677

4. Weiner BK, Fraser RD (1998) Spine update lumbar interbody cages. Spine 23:634-640

5. Rajaee SS, Bae HW, Kanim LE, Delamarter RB (2012) Spinal fusion in the United States: analysis of trends from 1998 to 2008. Spine (Phila Pa 1976) 37:67-76

6. Simon J, Longis PM, Passuti N (2017) Correlation between radiographic parameters and functional scores in degenerative lumbar and thoracolumbar scoliosis. Orthop Traumatol Surg Res 103(2):285-290

7. Herkowitz HN, Kurz LT (1991) Degenerative lumbar spondylolisthesis with spinal stenosis. A prospective study comparing decompression with decompression and intertransverse process arthrodesis. J Bone Joint Surg Am 73(6):802-808

8. Summers BN, Eisenstein SM (1989) Donor site pain from the ilium. A complication of lumbar spine fusion. J Bone Joint Surg Br 71(4):677-680

9. Vaccaro AR, Chiba K, Heller JG, Patel TCh, Thalgott JS, Truumees E, Fischgrund JS, Craig MR, Berta SC, Wang JC, North American Spine Society for Contemporary Concepts in Spine Care (2002) Bone grafting alternatives in spinal surgery. Spine J 2:206-215

10. Ehrler DM, Vaccaro AR (2000) The use of allograft bone in lumbar spine surgery. Clin Orthop Relat Res 371:38-45

11. Park DK, Kim SS, Thakur N, Boden SD (2013) Use of recombinant human bone morphogenetic protein-2 with local bone graft instead of iliac crest bone graft in posterolateral lumbar spine arthrodesis. Spine 38(12):E738-E747

12. Brown J, Heirs M, Higgins J, Mannion R, Rodgers M, Seneschall C, Simmonds M, Stewart L, Wright K (2013) Systematic review and meta-analysis of the safety and efficacy of recombinant human bone morphogenetic protein-2 (rhBMP-2) for spinal fusion. http:// yoda.yale.edu/sites/default/files/files/York\%20rhBMP-2\%20Fin al\%20Report.pdf. Accessed April 2018

13. Carlisle EM (1972) Silicon, an essential element for the chick. Science 178:619-621

14. Coathup MJ, Samizadeh S, Fang YS, Buckland T, Hing KA, Blunn GW (2011) The osteoinductivity of silicate-substituted calcium phosphate. J Bone Joint Surg Am 93(23):2219-2226

15. Alimi M, Navarro-Ramirez R, Parikh K, Njoku I, Hofstetter CP, Tsiouris AJ, Härtl R (2016) Radiographic and clinical outcome of silicate-substituted calcium phosphate $(\mathrm{Si}-\mathrm{CaP})$ ceramic bone graft in spinal fusion procedures. Clin Spine Surg 30(6):E845-E852

16. Hutchens SA, Campion C, Assad M, Chagnon M, Hing KA (2016) Efficacy of silicate-substituted calcium phosphate with enhanced strut porosity as a standalone bone graft substitute and autograft extender in an ovine distal femoral critical defect model. J Mater Sci Mater Med 27(1):20

17. Jenis LG, Banco RJ (2010) Efficacy of silicate-substituted calcium phosphate ceramic in posterolateral instrumented lumbar fusion. Spine 35(20):E1058-E1063

18. Licina P, Coughlan M, Johnston M, Ewing L, Pearcy M (2015) Comparison of silicate-substituted calcium phosphate (Actifuse ${ }^{\circledR}$ ) with rhBMP-2 (Infuse ${ }^{\circledR}$ ) in posterolateral instrumented lumbar fusion. Global Spine J 5(6):471-478

19. Chan O, Coathup MJ, Nesbitt A, Ho CY, Hing KA, Buckland T, Campion C, Blunn GW (2012) The effects of microporosity on osteoinduction of calcium phosphate bone graft substitute biomaterials. Acta Biomater 8:2788-2794

20. De Godoy RF, Hutchens S, Campion C, Blunn G (2015) Silicate-substituted calcium phosphate with enhanced strut porosity stimulates osteogenic differentiation of human mesenchymal stem cells. J Mater Sci Mater Med 26(1):5387

21. Fredericks DC, Petersen EB, Sahai N, Corley KG, DeVries N, Grosland NM, Smucker JD (2013) Evaluation of a novel silicate substituted hydroxyapatite bone graft substitute in a rabbit posterolateral fusion model. Iowa Orthop J 33:25-32

22. Smucker JD, Petersen EB, Al-Hili A, Nepola JV, Fredericks DC (2015) Assessment of SiCaP-30 in a rabbit posterolateral fusion model with concurrent chemotherapy. Iowa Orthop J 35:140-146

23. Glassman SD, Dimar JR, Carreon LY, Campbell MJ, Puno RM, Johnson JR (2005) Initial fusion rates with recombinant human bone morphogenetic protein-2/compression resistant matrix and a hydroxyapatite and tricalcium phosphate/collagen carrier in posterolateral spinal fusion. Spine 30(15):1694-1698

24. Hsu WK, Nickoli MS, Wang JC, Lieberman JR, An HS, Yoon ST, Youssef JA, Brodke DS, McCullough CM (2012) Improving the clinical evidence of bone graft substitute technology in lumbar spine surgery. Global Spine J 2(4):239-248

25. An HS, Lynch K, Toth J (1995) Prospective comparison of autograft vs. allograft for adult posterolateral lumbar spine fusion: differences among freeze-dried, frozen, and mixed grafts. J Spinal Disord 8:131-135

26. Guigui P, Ferrero E (2017) Surgical treatment of degenerative spondylolisthesis. Orthop Traumatol Surg Res 103(1S):S11-S20

27. Nagineni VV, James AR, Alimi M, Hofstetter C, Shin BJ, Njoku I Jr, Tsiouris AJ, Härtl R (2012) Silicate-substituted calcium phosphate ceramic bone graft replacement for spinal fusion procedures. Spine 37:E1264-E1272 
28. Truntzer J, Vopat B, Feldstein M, Matityahu A (2015) Smoking cessation and bone healing: optimal cessation timing. Eur J Orthop Surg Traumatol 25(2):211-215

29. Adams CL, Ogden K, Robertson IK, Broadhurst S, Edis D (2014) Effectiveness and safety of recombinant human bone morphogenetic protein-2 versus local bone graft in primary lumbar interbody fusions. Spine (Phila Pa 1976) 39(2):164-171

30. Andersen T, Christensen FB, Laursen M, Høy K, Hansen ES, Bünger C (2001) Smoking as a predictor of negative outcome in lumbar spinal fusion. Spine 26(23):2623-2628

31. Soriano JC, Revuelta MS, Fuente MF, Díaz IC, Ureña PM, Meneses RD (2010) Predictors of outcome after decompressive lumbar surgery and instrumented posterolateral fusion. Eur Spine J 19(11):1841-1848

32. Dawson E, Bae HW, Burkus JK, Stambough JL, Glassman SD (2009) Recombinant human bone morphogenetic protein-2 on an absorbable collagen sponge with an osteoconductive bulking agent in posterolateral arthrodesis with instrumentation. A prospective randomized trial. J Bone Joint Surg Am 91(7):1604-1613

33. Cho J, Lee J, Yeom J, Chang B, Yang J, Koo K, Hwang C, Lee K, Kim H, Lee C, Kim H, Suk K, Nam W, Han J (2017) Efficacy of

\section{Affiliations}

\section{Ciaran Bolger $^{1} \cdot$ Drew Jones ${ }^{1,2} \cdot$ Steven Czop ${ }^{2}$}

Ciaran Bolger

cbolger007@icloud.com

1 Beaumont Hospital, PO Box 1297, Beaumont Road, Dublin 9, Republic of Ireland
Escherichia coli-derived recombinant human bone morphogenetic protein-2 in posterolateral lumbar fusion: an open, active-controlled, randomized, multicenter trial. Spine J 17(12):1866-1874

34. Litrico S, Langlais T, Pennes F, Gennari A, Paquis P (2018) Lumbar interbody fusion with utilization of recombinant human bone morphogenetic protein: a retrospective real-life study about 277 patients. Neurosurg Rev 41(1):189-196

35. Fu R, Selph S, McDonagh M, Peterson K, Tiwari A, Chou R, Helfand M (2013) Effectiveness and harms of recombinant human bone morphogenetic protein-2 in spine fusion: a systematic review and meta-analysis. Ann Intern Med 158(12):890-902

36. Hansraj KK (2016) Stem cells in spine surgery. Surg Technol Int 29:348-358

Publisher's Note Springer Nature remains neutral with regard to jurisdictional claims in published maps and institutional affiliations.

Baxter Healthcare Corporation, One Baxter Parkway, Deerfield, IL 60015, USA 